\title{
Mobile transitions: Exploring synergies for urban sustainability research
}

(c) Urban Studies Journal Limited 2015 (c) (i) (9)

\section{Julia Affolderbach}

University of Hull, UK

\section{Christian Schulz}

University of Luxembourg, Luxembourg

\begin{abstract}
Urban sustainability approaches focusing on a wide range of topics such as infrastructure and mobility, green construction and neighbourhood planning, or urban nature and green amenities have attracted scholarly interest for over three decades. Recent debates on the role of cities in climate change mitigation have triggered new attempts to conceptually and methodologically grasp the cross-sectorial and cross-level interplay of enrolled actors. Within these debates, urban and economic geographers have increasingly adopted co-evolutionary approaches such as the social studies of technology (SST or 'transition studies'). Their plea for more spatial sensitivity of the transition approach has led to promising proposals to adapt geographic perspectives to case studies on urban sustainability. This paper advocates engagement with recent work in urban studies, specifically policy mobility, to explore conceptual and methodological synergies. It emphasises four strengths of an integrated approach: (I) a broadened understanding of innovations that emphasises not only processes of knowledge generation but also of knowledge transfer through (2) processes of learning, adaptation and mutation, (3) a relational understanding of the origin and dissemination of innovations focused on the complex nature of cities and (4) the importance of individual actors as agents of change and analytical scale that highlights social processes of innovation. The notion of urban assemblages further allows the operationalisation of both the relational embeddedness of local policies as well as their cross-sectoral actor constellations.
\end{abstract}

\section{Keywords}

assemblage, green innovations, policy mobility, transition studies, urban sustainability

Received May 2014; accepted March 2015

\section{Introduction}

Recent climate change debates have taken a semantic and conceptual turn away from sustainable development to sustainability

\section{Corresponding author:}

Julia Affolderbach, University of Hull, Geography,

Environment and Earth Sciences, Cottingham Road, Hull HU67RX, UK.

Email: j.affolderbach@hull.ac.uk 
transitions. This 'transition talk' about lowcarbon futures is now almost omnipresent in policy documents, the academic literature, and civil society and community activism promoting radical changes in and fundamental rethinking of production and consumption patterns. As part of their review on the research literature, Markard et al. (2012: 959) define work on sustainability transitions as focused on 'institutional, organizational, technical, social, and political aspects of farreaching changes in existing socio-technical systems (e.g., transportation and energy supply) which are related to more sustainable or environmentally friendly modes of production and consumption'.

Despite - or maybe because of - the holistic and inclusive character of this relatively new research effort, contributions are mainly focused on understanding particular subsets of (future) changes and their potentials. For example, green innovations and entrepreneurship, in particular in (alternative) energy and transportation infrastructure, are receiving increased attention in the field of transition studies (McCauley and Stephens, 2012; O'Neill and Gibbs, 2014; Raven and Geels, 2010; Späth and Rohracher, 2010; Verbong and Geels, 2010) with a growing interest in urban sustainability transitions (Bulkeley et al., 2011; Hodson and Marvin, 2010a).

Cities have long been promoted as optimum analytical scale and strategic agents of sustainable development, for example, in the fields of spatial planning, energy and transportation (Beatley, 2000; Beatley and Manning, 1997; Campbell, 1996; Nijkamp and Perrels, 1994). Our focus on cities is rooted in the urban geography literature and driven by an ongoing research project on urban greening initiatives that emphasises the complex relationships and assemblages that constitute cities based on various exchanges, adaptations and mutations of practices and models between agents (human and non-human).
Cities bear large potential to set the context for and be drivers of wider low-carbon transitions because of the larger size and number of public, economic and civil society institutions that turn them into hubs for investments, partnerships, education and culture. It is not merely the size and institutional thickness of cities that make urban areas potential catalysts for sustainable transitions. City governments are often forerunners in the promotion of climate mitigation strategies over-complying with or leading national or international norms and regulations, exemplified by Freiburg's low-energy building standards and Vancouver's Greenest City 2020 Action Plan. Climate change action, however, is not restricted to urban areas, as illustrated by the growing transition town movement which has been particularly successful in rural areas.

While contributions on sustainability transitions anchored in transition studies use technological innovations and modernisation processes as starting points to investigate drivers and processes of low-carbon transitions, urban geography and governance perspectives on cities and climate change are predominantly policy oriented. They question the processes behind and implications of policy innovations and new governance arrangements in low-carbon transitions. These spatially sensitive inquiries include investigations of multi-actor constellations and their inherent power relationships that highlight aspects of social sustainability and reject normative approaches to sustainability including technological 'fixes' (e.g. Krueger and Gibbs, 2007).

Both literatures recognise the coevolution of sociocultural and technical innovations and explicitly address the need to integrate the two perspectives through direct exchange and collaboration that offer different starting points for mutual synergies (Bulkeley et al., 2011; Rutherford and Coutard, 2014). Despite all recognitions of 
potential synergies, contributions remain restricted to relatively abstract conceptual proposals or, where they are more analytical, remain within their disciplinary comfort zone and respective research perspective.

By carving out potential synergies in transition studies and urban and economic geography, we argue in this paper that much could be gained from a more active and deeper discussion between transition studies and concepts in urban geography that does not elevate or prioritise socio-technical over socio-spatial perspectives a priori. The paper's main objective is to contribute to recent debates to bring geographical thinking into transitions studies and vice versa (Binz et al., 2014; Coenen and Truffer, 2012; Raven et al., 2012). Conceptually, we draw on recent work on urban policy mobility (McCann, 2011a; McCann and Ward, 2010; Peck and Theodore, 2010) to open up the multi-level perspective through a relational view that emphasises the assembled nature of cities.

From a relational, networked perspective, the idea of cities as incubators (or niches) for innovations requires critical examination. More precisely, we postulate to explore sustainability transitions through the patterns of learning and knowledge exchange including the creation, adaptation, reframing and redefinition of innovative concepts, technologies, practices and programmes to the extent they impact predominant discourses and regimes and induce changes in the urban energy and sustainability landscape.

We do not only seek to flesh out potential synergies between the two approaches, but also further differentiate the underlying notions of spatial relatedness and temporal dynamics. We seek to overcome the relatively rigid conceptualisation of space in transition studies with a dynamic understanding of spatial interactions which we draw from policy mobility and urban assemblage approaches. This perspective (a) reduces the risk to reify local context or to overrate single places as sole seedbeds for innovative approaches, (b) takes account of the complexity of interpersonal and interorganisational learning processes and knowledge creation in the realm of low-carbon initiatives including those of individual actors and (c) allows to grasp historical and synchronic causalities in the sense of coevolutionary events and conditions at different levels and (spatial) scales.

\section{Sustainability transitions, cities and space}

Over the past few years, scholars from transition and urban studies have started to engage in joint discussions in order to address questions on drivers and barriers in regional and urban low-carbon transitions (Bulkeley et al., 2011; Rutherford and Coutard, 2014). Thematically, contributions mainly focus on infrastructure systems and provision such as studies on the transportation and energy sector (Emelianoff, 2014; Hodson and Marvin, 2010a; McCauley and Stephens, 2012; Rohracher and Späth, 2014) and to a smaller extent on the building sector (O'Neill and Gibbs, 2014; Pickerill, 2011; Smith, 2007).

Conceptually and analytically, contributions can be loosely grouped distinguishing between two different entry points of analysis within transitions studies and urban governance studies. The first is focused on technological and technocratic aspects of environmental change based on the underlying assumption that economic restructuring and reductions in $\mathrm{CO}_{2}$ emissions require some form of technological innovations which are understood as products of processes of socio-technical co-evolution. The second starting point is anchored in urban geography and explains urban sustainable development through policy and governance processes that emphasise the diversity of 


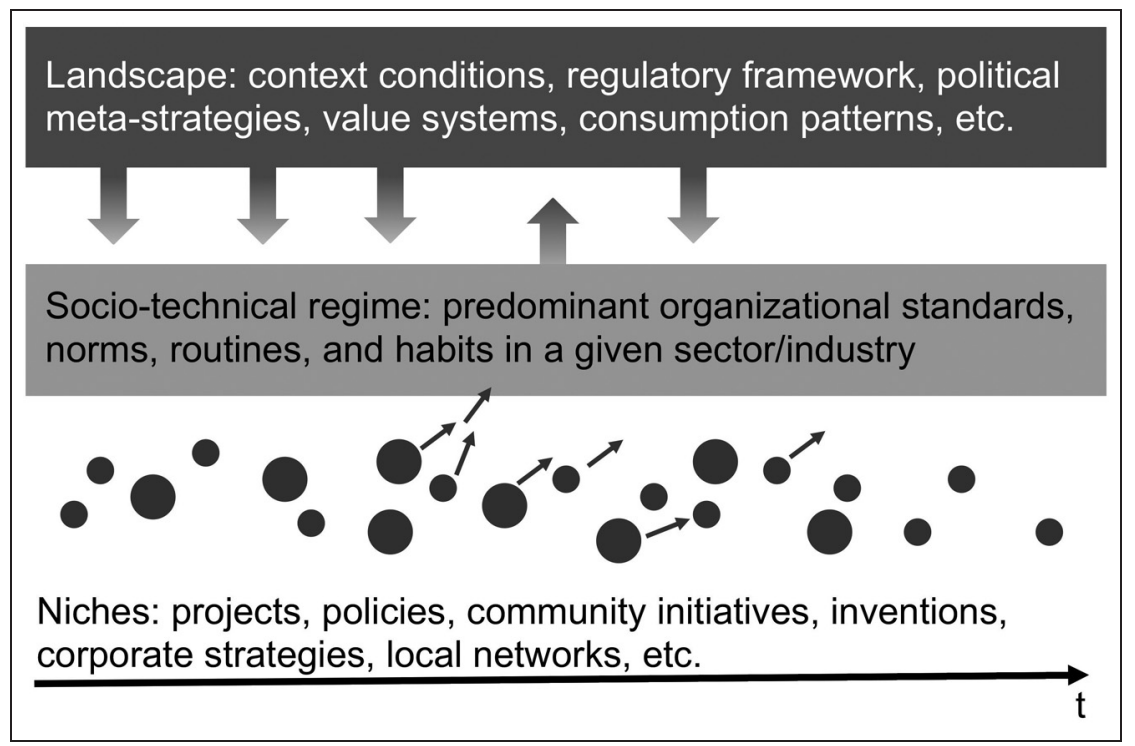

Figure I. Geels' multi-level perspective.

interests involved in decision-making, their uneven power relationships and aspects of political economy and ecology.

Research on urban sustainability transitions bridging the two fields is partly motivated by human geographers' recognition that socio-technical transition theory, in particular the multi-level perspective, can provide a 'useful way for geographers to address how societies can transition toward more sustainable futures' (Lawhon and Murphy, 2011: 355). The multi-level perspective model developed by Geels (2002) and widely adopted within transition studies provides a systematic framework to analyse the complex processes and actor relationships behind the rise and manifestation of sustainability transitions. It distinguishes between three hierarchic and mutually dependent levels: 'a micro-level of protected niches, functioning as test-beds for the emergence of new sociotechnical constellations, a meso-level of socio-technical regimes (such as energy systems) and a broader context of the sociotechnical landscape, which encompasses cultural norms, values and persistent sociotechnical structures' (Späth and Rohracher, 2010: 449) (Figure 1).

Niches are spaces where general rules usually market rules such as competition are different because of, for example, tax breaks and subsidies. These protected spaces allow the development, testing and improvement of new technologies and ideas until they are sufficiently robust to compete under regular conditions. However, niche innovations are only successfully translated to the regime and landscape level if changes at the other levels align. The translation of green innovations from the niche to regime and landscape level is not to be understood as a merely bottom-up transformation process from the niche to the regime level (Figure 1). Pressures or shocks on the regime (or landscape) level triggered through external events such as, for example, the Fukushima nuclear accident, increased oil prices or demographic change can bear transformative powers. The adoption of niche innovations in the mainstream requires the 
right alignment of conditions, their changes, shifts and contradictions between all three levels.

The multi-level model integrates an institutional perspective focused on relevant actor groups, framework conditions (political programmes, research policies, funding and tax systems, consumption practices, cultural meanings, etc.) and temporal dimensions that "can be used to shift the gaze of human geographers from particular artefacts or static socio-material patterns towards the co-evolution of technology and society, and the dynamic interactions between multiple social, political, and economic scales' (Lawhon and Murphy, 2011: 355). As such, it offers a heuristic analytical framework to unravel the complex nature of sustainability transitions.

While the mutual ties of socio-technical evolution are widely recognised, the rather rigid, hierarchical logic of the multi-level transition framework has been increasingly criticised. Geographers have been most critical about the lack of spatial sensitivity (Coenen et al., 2012; Hodson and Marvin, 2012; Raven et al., 2012; Truffer and Coenen, 2012), the strong technocratic focus, and neglect of the socio-political nature of urban sustainability transitions and power relationships between actors (Lawhon and Murphy, 2011; Meadowcroft, 2011; Smith et al., 2005; Walker and Shove, 2007) which fail to grasp the diversity of sustainability experiments and inventions, failed and successful, changing and stabilising, as well as spatial variations and hybrids.

One major limitation lies in the common (but maybe intuitive) equalisation of multiple levels with hierarchical spatial scales where socio-technical regimes and niches are conceptualised as separate entities that are being conflated with the national and local scale (Bulkeley et al., 2014). In a crossfertilising way, spatial concepts can help address limitations of socio-technical transition theory by opening up the clear-cut multi-level perspective to a relational thinking that blurs the boundaries between niches and regimes. For example, the multi-level perspective has mainly been employed to describe historical developments of how successful innovations spread but neglects to explain ongoing developments as well as where, how and through which actor constellations innovations come into being.

Human geographers have brought spatial dimensions into transition studies through a number of conceptual proposals (e.g. Coenen and Truffer, 2012; Raven et al., 2012 on Regional Studies; Bulkeley et al., 2014; Lawhon and Murphy, 2011 on Political Ecology). Gibbs and O'Neill (2014: 202) rightly argue that the proposals remain 'at a high level of abstraction themselves' and provide only limited empirical illustrations and evidence with a few exceptions including, for example, Anna Davies' work (2013) on cleantech clusters. Recent contributions to urban sustainability transitions contain more specific illustrations of how cities can be integrated into transition studies. Following the assumption prevalent in strategic niche management that 'sustainable innovation journeys can be facilitated by modulating of technological niches, i.e. protected spaces that allow nurturing and experimentation with the co-evolution of technology, user practices, and regulatory structures' (Schot and Geels, 2008: 538), the local and urban scale are seen as central to the ways political, administrative, economic and civil society actors co-determine the framework conditions for niche developments and regime changes. For example, contributions have highlighted the role of cities as sites of niche experiments (Coenen et al., 2010; Healy and Morgan, 2012; McCauley and Stephens, 2012), living laboratories (Evans, 2011; König, 2013), and 'sites of feasibility demonstrations' (Rohracher and Späth, 2014: 1427). 
Niches, however, are not autonomous or shielded spaces but rather shaped through spatial processes of exchange and learning. Numerous transnational and environmental associations including Local Governments for Sustainability (ICLEI) with its Cities for Climate Change Protection programme (CCP), the Climate Alliance, Energy Cities, and the C40 Cities Climate Leadership Group attest the prevalence of local and case-specific strategies in climate change mitigation initiatives that connect local and municipal actors around the globe (see also Healy and Morgan, 2012). ${ }^{1}$ Spatialised transition studies run the risk to reify space and spatial scales and to isolate case study regions from overarching contexts and the global diffusion of ideas, norms and ways of thinking in low-carbon transitions. Similarly, work in urban studies focused on the urban scale to deliver sustainable development bears the risk to isolate the local from other spatial scales through which environmental governance is exercised and to ignore 'wider social, economic and political processes which shape sustainability in urban places' (Bulkeley and Betsill, 2005: 58; Gibbs and Jonas, 2000).

In their analysis of infrastructure systems, Hodson and Marvin (2010b: 59) argue that "cities have differential capacity to be either "shapers of" or "shaped by" national transitions'. Following a similar line of thought, Rohracher and Späth (2014) in their analysis of energy transitions in Graz and Freiburg illustrate that cities cannot be solely conceptualised at the niche level. Rather they span across niches and regimes where respective urban and regional contexts may contribute to the emergence of a transition regime. In their empirically grounded paper that analyses the role of cities and regions in green innovations based on the example of green enterprises in Boston (USA), Gibbs and O'Neill (2014: 204-205) emphasise the need to move 'beyond a view of cities and regions as simply places for experimentation and demonstration [linking] together the niche with the regime and landscape' which calls for a dissolution of clearly bounded levels towards a relational perspective (see also Binz et al., 2014).

Another criticism of technocratic transition research lies in its focus on 'narrow social interests' and elite actors such as technical experts and entrepreneurs (Hodson et al., 2011: 198; Lawhon and Murphy, 2011) that ignores political contestations, inequalities in power relationships, and access to transition decisions, as well as failed experiments. There is hence a risk in the urban sustainability transition literature to ignore 'the multiple facets of 'the urban' that 'are both constructed on and imply quite different financial, socio-spatial, metabolic and governance configurations' (Coutard and Rutherford, 2011: 122).

\section{Policy mobilities and urban assemblages}

As outlined above, the concept of transition studies provides a promising access to understand the field of urban climate change mitigation in general and innovations in urban sustainability in particular. However, the concept - or at least its mainstream protagonists - seems to merely rely on technological innovations and a limited conceptualisation of space looking primarily at national contexts and their embedded and clearly localised niches. While the time dimension is well covered by transition studies' diachronic analytical perspective, much less is said about spatial dynamics, knowledge exchanges over longer distances and more complex forms of interactive learning. Conceptual perspectives in critical urban geography that advocate a relational understanding of space and recognise the 'contingent, historically specific, uneven, and dispersed nature of material and non-material flows' (Olds, 2001: 8, quoted in 
McCann and Ward, 2011: xxiv) have much to offer in this regard and can help open up the transition studies concept in order to overcome these limitations.

As to the notion of knowledge creation and transfer, we find the recently emerging concept of policy mobility helpful in addressing questions related to the 'who', 'where' and 'how' of knowledge transfer, learning, and social innovation (McCann, 2008; McCann and Ward, 2010, 2011; Peck and Theodore, 2010). The respective empirical studies show how urban policies are transformed as they travel and are adopted and adapted elsewhere. This perspective goes beyond simple policy transfer or unidirectional learning processes as they are often applied in political sciences, emphasising the ways policies 'mutate' (Stone, 1999) while they move from one place to another.

Furthermore, the approach focuses less on organisations (such as firms) but rather on actor groups, and even more on relevant individuals and their respective contexts in these processes. It denies the existence of localised best practices and models of good governance by introducing a relational view on continuous transformation and adaptation processes and their underlying driving forces. To date, policy mobility scholars have mainly focused on urban issues, while economic themes are only indirectly addressed, as for example in McCann and Ward's (2010) study on business improvement districts as a travelling urban policy. We think it is most timely to further explore the concept's potential for application in economic geography where it can complement existing concepts of (sustainable) innovation research.

More recently, the discussion on complementing policy mobility with work on urban assemblages has revealed some promising strands for further conceptualisation of the mobility perspective on innovation and urban processes (McCann and Ward, 2012;
McFarlane, 2009). It reinforces the conceptual understanding of cities as 'emergent translocal assemblages, or moments in more globally extensive flows' (McCann, 2011b: 144). According to McFarlane (2011: 652), 'assemblage does not separate out the cultural, material, political, economic, and ecological, but seeks to attend to why and how multiple bits-and-pieces accrete and align over time to enable particular forms of urbanism over others in ways that cut across these domains, and which can be subject to disassembly and reassembly through unequal relations of power and resource'. It thus goes much further than the descriptive assessment of how cities or other artefacts are constituted by different elements, and provides a conceptual dimension of processes and the interplay of 'practice, materiality, and emergence' (McCann, 2011b: 652; see Bulkeley et al., 2014 on social-material relations and urban transitions). Innovations in policy mobility thus go beyond actors' expertise or strategic knowledge travelling between places. They also include the actual adoption of technologies and the implementation of new organisational or procedural tools.

Studying the Nordhavn project in Copenhagen, a planned eco-city of global significance currently in its design phase, Anders Blok defines urban green assemblages as 'ensembles of heterogeneous actors, human and non-human, which orient themselves to the gradual redesign of urban eco-socio-technical relations in "green" (or "sustainable") directions' (Blok, 2013: 10). He pleads for a more systematic theorisation of and investigation into 'how urban knowledge is produced, translated and contested across specific urban sites, scales and relations' (Blok, 2013: 6). Anchored in the science and technology studies (STS) tradition, he advocates an actor network theoryinformed approach to the various dimensions and agencies underlying green urban policies (see also Temenos and McCann, 
2013). 'Like other urban assemblages, urban greening practices involve changing constellations of sites, objects and actors, from architects and engineers to regulators, greentech companies, civic associations and urban residents, coalescing at shifting levels of proximity and distance, from the "local" (e.g., a specific eco-house) to the "global" (e.g., climate change projections)' (Blok, 2013: 19). STS may thus provide inspiring insights into the interface between societal dynamics, political action, and research and innovation (e.g. Binz et al., 2014).

While policy mobility's conceptualisation of space has the central merit of avoiding any local or regional determinism and any overrating of localised best practices, the perspective is much weaker on the time dimensions of ongoing 'travels' of policies. Or, in Temenos and McCann's (2013: 352) words in their plea for allocating more time (and resources) to policy mobilities research: 'careful analysis is necessary to overcome concerns of "presentism" - a narrow focus on current successful policies, without regard for what has come before, for what was perhaps unsuccessful, or for alternative policy narratives'. Policy mobility provides a less comprehensive picture since it is prone to neglect processes that emerge in parallel without necessarily interfering with policy strategies and mobile concepts (e.g. technological innovations, purely business-driven changes).

Local assemblages can help overcome this as they are not only snapshots in a given moment in time where particular actor constellations, currents and ideas come together and shape the disposition of a city or region. They do also comprise the multiple legacies of past events and evolutions in a particular context, such as place-specific experiences (shock events, break-throughs, failures) and related attitudes and value systems. One could assume that the historical trajectories of local policies as well as biographical experiences of key actors have an influence on the current disposition and consequently on the outcome of strategic decision-making (see for example the remarkably detailed work of Emilianoff and Stegassy, 2010, who traced numerous actors across Europe in order to understand their motivation for and contributions to urban sustainability strategies). This further supports the contingency hypothesis of both innovation research and the policy mobility approach.

\section{Mobile transitions?}

The juxtaposition of policy mobility and transition studies as illustrated in Figure 2 offers starting points to critically examine and open up assumptions and definitions underlying the analysis of sustainability transitions. The synoptic comparison of the respective strengths of the concepts highlights their complementarities and is partly inspired by work that addresses the convergence between localised transitions and sustainability innovations and more relational perspectives on knowledge creation and the dissemination of appropriate strategies.

First, policy mobility allows a broadening of transition studies' understanding of knowledge creation and transfer (and vice versa). It extends the understanding of (mainly technological and economic) innovations in a socio-spatial sense to include mobilised knowledge, transformations and mutations that reflect messy, contested and complex realities. Policy mobility offers a more incremental understanding of continuous learning based on adaptation, imitation and mutation of pre-existing ideas and concepts. It focuses on 'how key actors, ideas and technologies are actively brought together into productive co-presence in cities, in how certain absences are also present in policymaking, as actors in one place refer to models elsewhere as they construct "local policies"' (McCann, 2011b: 143). As such, it 


\begin{tabular}{|lll|}
\hline & Policy Mobility & Transition Studies \\
\hline What? & Mobility/transfer of knowledge & Knowledge creation \\
& Socio-spatial(-political) processes & Socio-technical processes \\
How? & Learning, adaptation \& mutation & Radical niche innovation \\
Where? & Relational & Localised \\
Who? & Individuals \& actor groups & Actor networks \& \\
& & institutional structures \\
\hline
\end{tabular}

Figure 2. Synopsis of main conceptual dimensions of policy mobility and transition studies.

includes exclusions and absences of innovations that lie idle, those that are not transferred. As mentioned above, cities can be understood as 'assemblages' of exchanges and transformations through actors, ideas and parts from elsewhere that are aligned and reassembled in specific localities. Thus there is an outbound dimension of local assemblages, or, in other words, in any moment of time, the then urban assemblage is both the outcome of local interactions and of external influences. Newly gained or developed knowledge is subject to recombination with pre-existing on-site knowledge ('reassemblage') that can lead to (at least gradual) innovations.

Second, and building up on this point, sustainability transition cannot be clearly defined through the degree to which successful innovations are adopted and change the status quo. Transition studies' primary interest lies in identifying the mechanisms behind and framework conditions for radical niche innovations and how they enter the regime level and herewith become influential triggers of changes up to the landscape level. This conception is based on successful innovations and caters - at least to a certain extent - to idealised models of best practices, good governance and cutting-edge technologies that falsely lead to views of transition processes as "singular, universal and linear pathways to the "zero-" or "post-carbon city"' (Rutherford and Coutard, 2014: 1366).

A policy mobility perspective questions this rather structuralist, predetermined and unidirectional conception of sustainability transitions. Policy mobility suggests that sustainability transitions are much more diverse and consist of parallel processes of divergence and convergence that seek to explain a more nuanced understanding of success and its limits including immobilities, exclusions and unevenness of the transfer and creation of ideas, actors and knowledge. It deconstructs assumptions of rational evaluations behind the adoption of innovative ideas with a focus on how and why ideas, actors, 
models, technologies are transferred and transformed on the way. From a transition studies perspective, successful innovations are only those that become established at the regime (and eventually) the landscape level. But as McCann (2011a: 121) argues, 'It would be too simple to assume that certain best practices, cities, and consultants "naturally" rise to the top'. Their success is largely determined by socio-spatial conditionality. '[P]olicy mobilities [and other knowledge innovations] need to be understood as produced by the social, spatial, institutional, ideological and political contexts in which they are developed, applied, transferred and adopted. As such, the study of the sites and processes of transfer must include analysis of the forces that condition them' (McCann, 2011a: 121). This is particularly relevant for local experiments that arise out of contextspecific situations or contested innovations that are not supported by a large number of the public and require time to receive societal approval and acceptance.

Third, the different though compatible conceptualisations of space, with transition studies scholars stressing the role of local or regional settings, and policy mobility thinking in more relational terms, bear potential as well as challenges for their combination. A relational perspective questions the hierarchies and logics of the multi-level perspective where innovations are clearly situated within contained niches instead pointing to how they develop and spread in different ways connecting formerly unconnected places, actors and practices (Binz et al., 2014). Such a perspective dissolves the clear boundaries of niches and regimes, changes the relationship between different levels and disconnects the alignment and hierarchy between distinct levels and spatial scales. Even further, if transition processes are understood as assembled or simultaneously co-produced by agents at multiple scales, we need to question the origin of innovations and inherently the role of 'niches' as test beds. For example, policy mobility can help prevent the former from overstating local or regional contexts while transition studies offers a structural framework that includes parallel as well as successive developments.

A current example of a climate policyrelated assemblage is the European Covenant of Mayors, a network initiative launched by the European Commission in 2008 and supported by both the European Parliament and the Committee of the Regions. In October 2014, it counted more than 6000 signatories across Europe, i.e. municipalities committing themselves 'within a year following their signature (...) to implement Sustainable Energy Action Plans on their territory, with the aim of cutting $\mathrm{CO}_{2}$ emissions by at least $20 \%$ by 2020 ' (Covenant of Mayors, 2014a). The municipalities can receive scientific and technical assistance from the European Commission's Joint Research Centre and financial support from the European Investment Bank. Further, a wide range of institutional actors (mainly from the energy sector) joined the Covenant as associated members (Covenant of Mayors, 2014b). Though it might be too early to estimate the outcomes and impact of the initiative, the rapidly growing number of signatories indicates a high interest at the municipal level in using this framework and its manifold interfaces within and across administrative levels and sectors. It offers opportunities for unusual constellations comprising EU, local and (corporate) institutional actors and mirrors the remarkable 'growth in the scale and nature of municipal responses' (Bulkeley et al., 2012: 46).

Similarly, Emelianoff (2004) highlights how - in the context of urban sustainability strategies - the interplay between municipal initiatives and aspirations, European lowcarbon policies and programmes as well as related research endeavours has gained momentum and led to paradigmatic shifts in 
European urban policies and urbanism. Complementary to these strands of literature, the debate around 'civic innovation' (Agyeman and Briony, 2003; Sirianni and Friedland, 2001) through its emblematic case studies (e.g. Save The Bay in Rhode Island) illustrates how grassroots initiatives can develop into cross-sectoral civic associations with a high reflexive capacity triggering innovation through cooperation with a broad variety of actors.

Fourth, and in terms of agents, transition studies tend to focus both conceptually and empirically on actor networks and institutional structures, while policy mobility highlights the role of individual actors or smaller organisational units and their respective trajectories and learning biographies. A more nuanced, actor-centred approach allows addressing a number of the weaknesses outlined above. Transition research runs the risk to prioritise technocratic elites, established institutions and governance structures neglecting political contestations. A focus on individual actors and actor groups in their respective contexts - while similarly prone to prioritising certain actors - is more sensitive to power imbalances between agents of change revealing localised practices, hybrids and failed attempts. A social approach to knowledge creation and learning that understands individuals as carriers of knowledge and innovation and traces personal pathways offers a relational understanding of drivers behind sustainability innovations that crisscross and connect different places and scales and hence helps overcome definitions of localised niches and hierarchical scalar thinking. Further, and maybe most obviously, using the analytical scale of the individual actor provides a variety of methodological tools for sustainability research that can be used to help fill the empirical void.

Despite the outlined complementarities of the two concepts, the actual challenge for both the spatially sensitive application of transition studies as well as its conjunction with the policy mobility approach lies in their joint empirical application. Research in transition studies has successfully applied longitudinal studies and developed solid methodologies based on archive work and historical statistics. However, O'Neill and Gibbs (2014) state a simple lack of empirical studies when it comes to the spatial dimension of socio-technical transitions. This includes not only a limited amount of reliable results, but also a potentially insufficient debate about methodological implications due to the complexity of the concepts and research objects. Contributions to policy mobility offer a range of empirically grounded case studies and experiment with promising methods including detailed ethnographic studies of knowledge networks (including the tracking of individual actors' 'learning' paths), observations and factfinding trips, and other techniques going beyond the usual repertoire in urban and economic geography (McCann, 2011a: 122). As mentioned above, its methodological shortcomings lie rather in the (deliberate) exclusion of non-mobile (though relevant) policies that mark a study site.

Further integration of the two perspectives in operational terms will require both a multiple or mixed methods approach and a well reflected definition of appropriate study sites, including the geographical scope. Multi-actor and multi-sector perspectives might help to grasp the various articulations, flows and tensions between (the three) levels and serve to identify the pertinent drivers for and barriers to change and promising niche developments. Although they imply a certain multi-scalar thinking, the latter must not be understood as a sound geographical approach but could be realised through a relational spatial understanding, which allows the translocal tracing of processes at the niche, regime and landscape level. A multi-sited ethnography might help to 
compare different regional settings and trajectories and to unravel connections between different places.

Qualitative research methods hold highest potential for an in-depth exploration of the context conditions of socio-technical coevolutions and the core parameters determining the mobilities of innovations and relevant strategic approaches. They may include techniques such as narrative and semi-structured interviews, (participatory) observation, as well as more interactive formats such as Delphistyle group discussions or knowledge cafés. Given the crucial role of decision makers and carriers of information, particular emphasis should be placed on the micro-level of (individual) key actors within organisations.

A further challenge certainly lies in the conceptualisation of space when it comes to define the geographical focus of case study research. As indicated in Figure 2, transition studies research to date mostly follows contiguous national or regional territories as study sites, administratively defined and reflected in official statistics and formal policies, while policy mobility resorts to a relational understanding of interconnected and interacting places in a global space, i.e. a systematic consideration of extra-regional relationships and flows as potentially central components of the localised configuration (or assemblage). These can only be grasped with a respective methodology avoiding any territorial trap or spatial predetermination of analytical objects.

If urban arenas are identified as appropriate scale for the analysis of sustainability transitions, they need to be understood in the sense of interrelated and internationally embedded spatial settings in which actors of interest are located and visible innovation in the respective sector occurs rather than contiguous territories. This means that novelties identified must neither have their origins in that region, nor that innovation processes and knowledge creating networks are limited to a particular territory. The challenge consists in tackling highly complex and dynamic trajectories and interactions which require a spatial 'openness' in terms of empirical scope. Potentially, case study regions might only be starting points for exploratory studies then leading to changing and broadening scopes and scales of analysis. Consequently, this conceptualisation of space requires a flexible research design and a hermeneutic openness towards incremental adaptations and extensions of a chosen approach as research progresses.

\section{Conclusion}

As 'transition talk' has entered debates in human geography and inspired a growing set of studies on urban sustainability transitions, a number of pleas and conceptual proposals have sought to link transition studies with the geographic literature. In support of this work, we argued in this paper that much could be gained from a more active and deeper discussion between transition studies and concepts in urban geography. While the multi-level perspective offers a strong and structured analytical tool and heuristic framework to (re)construct socio-technical transitions towards low-carbon futures, it suffers from a number of limitations including a certain 'geographical naïveté' (Lawhon and Murphy, 2011: 362) and fails to properly consider the social and political nature of sustainability transitions.

Insights from the policy mobility literature can help address these shortcomings redirecting the focus on the assembled nature of cities, the translocal character of 'the urban', the role of actors as carriers of knowledge, practices and patterns of engagement, and processes of learning and knowledge creation. The proposed perspective challenges our understanding and expectations of the ways in which sustainability transitions will be substantiated often 
associated with a somewhat homogenous shift from the existing carbon intensive status quo to technologically driven low-carbon alternatives. Socio-spatial perspectives question these assumptions and suggest that sustainability initiatives and innovations may not take the form of the current widely promoted new technological fixes or panaceas (see also discussions on the 'green economy' e.g. Bailey and Caprotti, 2014; Bina, 2013). Rather, sustainability transitions may take the form of assemblages as illustrated by the Covenant of Majors that consist of a variety of forms and solutions, successful and unsuccessful ones.

Bulkeley et al. (2014: 1472) contest the conceptualisation of 'a decisive transition from one socio-technical system to another' and talk about 'critical junctures' that 'both contest and reproduce the dominant "postpolitical" climate change frame' (Bulkeley et al., 2014: 1472). Current climate change initiatives and experiments suggest that the 'trial and error' phase may take much longer, be more contested, and constitute very different, spatially unique assemblages of sustainability innovations and mutations. These refer not only to cross-sectorial and cross-level actor constellations, partly spanning across spatial scales and linking distant localities, but also include the power dimensions of interaction (Allen and Cochrane, 2007) requiring micro-analytical views of underlying mechanisms and determinants. An integrated perspective allows not only to complement the mere descriptive assessment of assemblages with a dynamic understanding of (changing) contexts, but also to overcome the static character of the multi-level perspective, widely criticised for its rigid reification of levels and their distinct notions. Further, it helps to depict the actual agency of individuals and organisations and thus to better understand the key factors and processes in sustainability transitions. This includes engagement with civic and social innovations (Agyeman and Briony, 2003; Sirianni and Friedland, 2001).

In more general terms, more attention should be paid to an appropriate operationalisation of space, scale and relational patterns in transition research in order to fully explore the competencies and particular contributions through which geography could feed into the ongoing and strongly interdisciplinary debate. Empirically focused on local arenas, the concept of assemblage permits to encompass the impetus of external actors and the influence of strategic knowledge developed in other places. Although the notion of assemblage can be criticised for its lack of conceptual rigour and difficulties with its operationalisation, it provides a promising heuristic combining central elements of both the MLP and policy mobility approaches when looking at individuals, interactions, and resulting agency.

The concepts of regime and landscape derived from the MLP allow to both further operationalise the notion of structure and framework influencing the mobilisation an adaptation of policies, "the technocratization of policy-making and policy transfer' (Temenos and McCann, 2013: 353) and to provide a concrete heuristic for identifying and evaluating agencies and their impact at the respective levels. In accordance with Temenos and McCann (2013: 350-351), this offers a way to integrate multi-scalar dimensions of local policy making into urban sustainability research.

It is thus not only to contribute to scholarly discourses, but also to engage with practitioners and decision makers. Provision of knowledge and evidence on the actual pathways and biographies of successful urban policies provides a basis to reconsider existing strategies without overrating the importance of local framework conditions in order to (1) facilitate the exchange and critical conversation with practitioners and decision makers in other city regions and (2) develop 
a systemic understanding of influential levels and scales, without reifying the latter.

A wide range of topics regarding sustainable transitions might serve as test beds for this recombined approach including multifaceted energy policies for low-carbon transitions (encompassing the decentralised use of renewables, low/zero/plus energy buildings, district heating, smart grids), transport and mobility issues, food security and urban farming, and more organisational issues such as community planning, co-housing, or solidary economies and local sharing schemes. All of these are identified as highly innovative fields showing dynamics of rapid and international dissemination as well as re-adaptation of promising concepts.

\section{Acknowledgements}

We would like to thank the reviewers for their valuable comments and James Murphy for feedback on an early version. All remaining errors remain our own.

\section{Funding}

The research is jointly funded by the National Research Fund Luxembourg (FNR) and the German Research Foundation (DFG) - INTER/ DFG/12/01/GREENREGIO.

\section{Note}

1. We do not seek to suggest here that urban areas are more likely to organise on a relational basis than non-urban areas, which can be similarly characterised by networked relational ties.

\section{References}

Agyeman J and Briony A (2003) The role of civic environmentalism in the pursuit of sustainable communities. Journal of Environmental Planning and Management 46(3): 345-363.

Allen J and Cochrane A (2007) Beyond the territorial fix: Regional assemblages, politics and power. Regional Studies 41(9): 1161-1175.
Bailey I and Caprotti F (2014) The green economy: Functional domains and theoretical directions of enquiry. Environment and Planning A, 46: 1797-1813.

Beatley T (2000) Green Urbanism: Learning from European Cities. Washington, DC: Island Press.

Beatley T and Manning K (1997) The Ecology of Place: Planning for Environment, Economy, and Community. Washington, DC: Island Press.

Bina O (2013) The green economy and sustainable development: An uneasy balance? Environment and Planning C: Government and Policy 31: 1023-1047.

Binz C, Truffer B and Coenen L (2014) Why space matters in technological innovation systems - Mapping global knowledge dynamics of membrane bioreactor technology. Research Policy 43: 138-155.

Blok A (2013) Urban green assemblages: An ANT view on sustainable city building projects. Science \& Technology Studies 26(1): 5-24.

Bulkeley H and Betsill MM (2005) Rethinking sustainable cities: Multilevel governance and the 'urban' politics of climate change. Environmental Politics 14(1): 42-63.

Bulkeley H, Castán Broto V and Edwards G (2012) Bringing climate change to the city: Towards low carbon urbanism? Local Environment 17(5): 545-551.

Bulkeley H, Castán Broto V, Hodson M, et al. (eds) (2011) Cities and Low Carbon Transitions. London and New York: Routledge.

Bulkeley H, Castán Broto V and Maassen A (2014) Low-carbon transitions and the reconfiguration of urban infrastructure. Urban Studies 51(7): 1471-1486.

Campbell S (1996) Green cities, growing cities, just cities? Urban planning and the contradictions of sustainable development. Journal of the American Planning Association 62(3): 296-312.

Coenen L and Truffer B (2012) Places and spaces of sustainability transitions: Geographical contributions to an emerging research and policy field. European Planning Studies 20(3): 367-374.

Coenen L, Benneworth P and Truffer B (2012) Toward a spatial perspective on sustainability transitions. Research Policy 41(6): 968-979. 
Coenen L, Raven R and Verbong G (2010) Local niche experimentation in energy transitions: A theoretical and empirical exploration of proximity advantages and disadvantages. Technology in Society 32: 295-302.

Coutard O and Rutherford J (2011) The rise of post-networked cities in Europe? Recombining infrastructural, ecological and urban transformations in low carbon transitions. In: Bulkeley H, Castán Broto V, Hodson M, et al (eds) Cities and Low Carbon Transitions. London and New York: Routledge, pp. 107-125.

Covenant of Mayors (2014a) Signatories. Available at: http://www.covenantofmayors.eu/ about/ signatories_en.html (accessed 11 October 2014).

Covenant of Mayors (2014b) Associated Partners. Available at: http://www.covenantofmayors.eu/Associated-Partners,263.html (accessed 11 October 2014).

Davies A (2013) Cleantech clusters: Transformational assemblages for a just, green economy or just business as usual? Global Environmental Change 23: 1285-1295.

Emelianoff C (2004) L'urbanisme durable en Europe: à quel prix? Ecologie \& politique 29: 21-36.

Emelianoff C (2014) Local energy transition and multilevel climate governance: The contrasted experiences of two pioneer cities (Hanover, Germany, and Växjö, Sweden). Urban Studies 51(7): 1378-1393.

Emilianoff C and Stegassy R (2010) Les pionniers de la ville durable: récits d'acteurs, portraits de villes en Europe. Paris: Autrement.

Evans JP (2011) Resilience, ecology and adaptation in the experimental city. Transactions of the Institute of British Geographers 36(2): 223-237.

Geels F (2002) Understanding the Dynamics of Technological Transitions: A Co-evolutionary and Socio-technical Analysis. Enschede: Twente University Press.

Gibbs D and Jonas A (2000) Governance and regulation in local environmental policy: The utility of a regime approach. Geoforum 31(3): 299-313.

Gibbs D and O'Neill K (2014) The green economy, sustainability transitions and transition regions: A case study of Boston. Geografiska Annaler: Series B 96(3): 201-216.
Healy A and Morgan K (2012) Spaces of innovation: Learning, proximity and the ecological turn. Regional Studies 46(8): 1041-1053.

Hodson M and Marvin S (2010a) Can cities shape socio-technical transitions and how would we know if they were? Research Policy 39: 477-485.

Hodson M and Marvin S (2010b) World Cities and Climate Change. Maidenhead: Open University Press.

Hodson M and Marvin S (2012) Mediating low-carbon urban transitions? Forms of organization, knowledge and action. European Planning Studies 20(3): 421-439.

Hodson M, Marvin S, Bulkeley H, et al. (2011) Conclusion. In: Bulkeley H, Castán Broto V, Hodson M, et al (eds) Cities and Low Carbon Transitions. London and New York: Routledge, pp. 198-202.

König A (ed.) (2013) Regenerative Sustainable Development of Universities and Cities: The Role of Living Laboratories. Cheltenham: Edward Elgar Publishing.

Krueger R and Gibbs D (eds) (2007) The Sustainable Development Paradox: Urban Political Economy in the United States and Europe. New York: Guilford Press.

Lawhon M and Murphy JT (2011) Socio-technical regimes and sustainability transitions insights from political ecology. Progress in Human Geography 36(3): 354-378.

McCann E (2008) Expertise, truth, and urban policy mobilities: Global circuits of knowledge in the development of Vancouver, Canada's 'four pillar' drug strategy. Environment \& Planning A 40: 885-904.

McCann E (2011a) Urban policy mobilities and global circuits of knowledge: Toward a research agenda. Annals of the Association of American Geographers 101(1): 107-130.

McCann E (2011b) Veritable inventions: Cities, policies and assemblage. Area 43(2): 143-147.

McCann E and Ward K (2010) Relationality/territoriality: Toward a conceptualization of cities in the world. Geoforum 41: 175-184.

McCann E and Ward K (eds) (2011) Mobile Urbanism: Cities \& Policymaking in the Global Age. Minneapolis, MN: University of Minnesota Press. 
McCann E and Ward K (2012) Assembling urbanism: Following policies and 'studying through' the sites and situations of policy making. Environment and Planning $A$ 44: 42-51.

McCauley SM and Stephens JC (2012) Green energy clusters and socio-technical transitions: Analysis of a sustainable energy cluster for regional economic development in central Massachusetts, USA. Sustainability Science 7(2): 213-225.

McFarlane C (2009) Translocal assemblages: Space, power and social movements. Geoforum 40: 561-567.

McFarlane C (2011) The city as assemblage: Dwelling and urban space. Environment and Planning D 29: 649-671.

Markard J, Raven R and Truffer B (2012) Sustainability transitions: An emerging field of research and its prospects. Research Policy 41(6): 955-967.

Meadowcroft J (2011) Engaging with the politics of sustainability transitions. Environmental Innovation and Societal Transitions 1(1): 70-75.

Nijkamp P and Perrels A (1994) Sustainable Cities in Europe. London: Routledge.

O'Neill K and Gibbs D (2014) Towards a sustainable economy? Socio-technical transitions in the green building sector. Local Environment 19(6): 572-590.

Peck J and Theodore N (2010) Mobilizing policy: Models, methods, and mutations. Geoforum 41: $169-174$.

Pickerill J (2011) Building liveable cities: Urban low impact development as low carbon solutions? In: Bulkeley H, Castán Broto V, Hodson $\mathrm{M}$, et al (eds) Cities and Low Carbon Transitions. London: Routledge, pp: 178-197.

Raven R and Geels FW (2010) Socio-cognitive evolution in niche development: Comparative analysis of biogas development in Denmark and the Netherlands (1973-2004). Technovation 30(2): 87-99.

Raven R, Schot J and Berkhout F (2012) Space and scale in socio-technical transitions. Environmental Innovation and Societal Transitions 4: 63-78.
Rohracher H and Späth P (2014) The interplay of urban energy policy and socio-technical transitions: The eco-cities of Graz and Freiburg in retrospect. Urban Studies 51(7): 1415-1431.

Rutherford J and Coutard O (eds) (2014) Special issue: Urban energy transitions: Places, processes and politics of socio-technical change. Urban Studies 51(7).

Schot J and Geels FW (2008) Strategic niche management and sustainable innovation journeys: Theory, findings, research agenda, and policy. Technology Analysis \& Strategic Management 20(5): 537-554.

Sirianni C and Friedland L (2001) Civic Innovation in America. Community Empowerment, Public Policy, and the Movement for Civic Renewal. Berkeley, Los Angeles, London: University of California Press.

Smith A (2007) Governance lessons from green niches: The case of eco-housing. In: Murphy P (ed.) Governing Technology for Sustainability. London: Earthscan, pp: 89-109.

Smith A, Stirling A and Berkhout F (2005) The governance of sustainable socio-technical transitions. Research Policy 34(10): 1491-1510.

Späth P and Rohracher H (2010) 'Energy regions': The transformative power of regional discourses on socio-technical futures. Research Policy 39(4): 449-458.

Stone D (1999) Learning lessons and transferring policy across time, space and disciplines. Politics 19(1): 51-59.

Temenos C and McCann E (2013) Geographies of policy mobilities. Geography Compass 7(5): 344-357.

Truffer B and Coenen L (2012) Environmental innovation and sustainability transitions in regional studies. Regional Studies 46(1): 1-21.

Verbong GPJ and Geels FW (2010) Exploring sustainability transitions in the electricity sector with socio-technical pathways. Technological Forecasting and Social Change 77(8): 1214-1221.

Walker G and Shove E (2007) Ambivalence, sustainability and the governance of sociotechnical transitions. Journal of Environmental Policy \& Planning 9(3-4): 213-225. 